
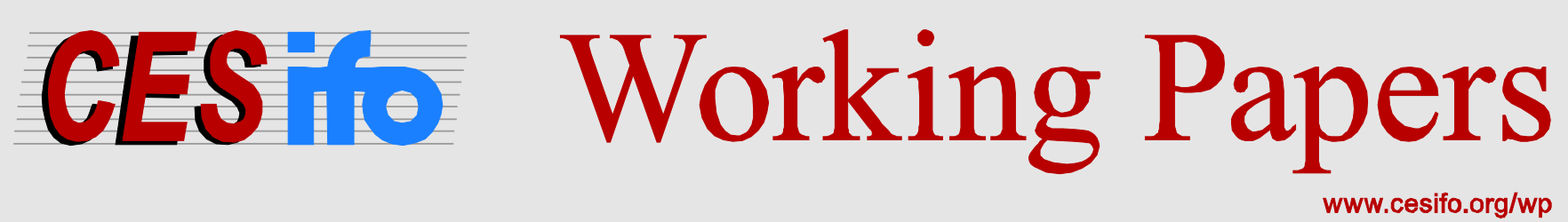

\title{
Evolutionary Stability in Fiscal Competition
}

\author{
Andreas Wagener \\ CESIFO WORKING PAPER NO. 5791 \\ CATEGORY 1: PuBlic FinANCE \\ MARCH 2016 \\ An electronic version of the paper may be downloaded \\ - from the SSRN website: \\ - from the RePEc website: \\ - from the CESifo website: \\ wWw.SSRN.com \\ www.RePEc.org \\ www.CESifo-group.org/wp
}




\title{
Evolutionary Stability in Fiscal Competition
}

\begin{abstract}
In fiscal interaction, a policy is evolutionarily stable if, once adopted by all governments, jurisdictions that deviate from it fare worse than those that stick to it. Evolutionary stability is the appropriate solution concept for models of imitative learning (policy mimicking). We show that evolutionarily stable strategies implement identical allocations, regardless of whether jurisdictions use tax rates or expenditure levels as their strategy variable. This is in contrast to the observation that the allocations in the Nash equilibria of games played in tax rates or expenditure levels differ from one another. With evolutionary play, jurisdictions set taxes and expenditures competitively, i.e., they behave as if they were all negligibly small.
\end{abstract}

JEL-Codes: H770, H720, C730.

Keywords: tax and expenditure competition, finite-player ESS, policy equivalence.

Andreas Wagener

School of Economics and Management

University of Hannover

Koenigsworther Platz 1

Germany - 30167 Hannover

wagener@sopo.uni-hannover.de 


\section{Introduction}

In economically integrated settings, jurisdictions at the same tier of a federation are strategically linked: with mobile people, goods or factors, policies implemented in one jurisdiction affect the economic performance in other jurisdictions, giving rise to fiscal games. It is well-known that the choice of policy variable matters for the outcomes of such games: even in simple settings where public expenditures are financed through a single tax on a mobile tax base, the Nash equilibria of games where governments use tax rates as their policy variable generate different allocations than equilibria where governments operate with expenditure levels. For example, if governments tax-finance local public goods, competition in expenditures is sharper than in tax rates: the provision levels of public goods are lower in expenditure competition than in tax competition (Wildasin, 1988, 1991). Similarly, if governments tax-finance inputs that increase productivity in local production, the provision levels in Nash equilibrium differ between the tax game and the expenditure game - though it is unclear which type of competition is fiercer (BayindirUpmann, 1998). For decentralized redistribution with mobile beneficiaries, equilibria are different when governments choose transfer payments to the poor and when tax rates on the rich as their instruments (Koethenburger, 2014).

The non-equivalence of policy instruments is important in a number of issues in fiscal federalism: for the necessity and desirability of policy coordination (Zissimos and Wooders, 2008), for the potential superiority of a policy mix over a single policy instrument (Hauptmeier et al., 2012), for the effects and design of fiscal equalization schemes (Hindricks et al., 2008; Koethenbuerger, 2011), for commitment issues in fiscal competition etc.

The discussion so far refers to Nash equilibria of fiscal games. This solution concept presupposes that policies are set as best responses to other governments' policies, where "best" is measured in terms of jurisdictions' own payoffs. Nash play requires complete knowledge of the game (at least of the mapping from policies to payoffs).

In this paper, we depart from Nash play and study (finite-player) evolutionary stability in fiscal competition. A policy is an evolutionarily stable strategy (ESS) if, once adopted by all players, it cannot be successfully invaded by a small number of deviations to a 
different policy (for a formal definition see Schaffer, 1988, or Section 3). The basic idea of evolutionary stability in fiscal interactions is that more successful policies will, in quite general dynamics, diffuse faster over time than not-so-successful policies and will eventually take over in the set of jurisdictions. Once achieved, an ESS is immune against rare and single policy experiments ("mutations") in the sense that mutant jurisdictions always earn lower payoffs than the jurisdictions that stick with the ESS.

Evolutionary stability has recently been applied to games among governments (Sano, 2012; Wagener, 2013; Ania and Wagener, 2014; Philipowski, 2015). It can be motivated in a variety of ways. First, evolutionary stability is the equilibrium prediction for games played with the objective of maximizing relative payoffs. In models of fiscal interaction, this captures yardstick competition, relative performance concerns, and policies motivated by keeping up with other jurisdictions. Second and more importantly, evolutionary stability is a useful concept in models of imitative learning (see, e.g., Fudenberg and Imhof, 2006). Being an ESS is a necessary property for the rest points in a wide class of dynamic processes that might arise in fiscal interaction: in finite-population games, the dynamics of policy mimicry, imitate-the-best behavioral rules with occasional policy experimentation and various other types of learning, imitation, and diffusion will reach stability in the long run only at evolutionarily stable strategies (for a survey, see Alòs-Ferrer and Schlag, 2010). ${ }^{1}$ The empirical observation that jurisdictions often copy one another in their policies and the Hayekian notion that federations are policy laboratories and fiscal decentralization initiates discovery procedures for good policies anecdotally and theoretically suggest that fiscal interaction indeed works through imitation-and-experimentation dynamics. In such cases, evolutionary approaches lend themselves to a belief-free analysis of fiscal interaction, requiring from policy makers less than full rationality, understood as payoff maximization with complete knowledge (and the use thereof) of the true economic model, the mapping between policies and payoffs, and all other relevant information.

We compare the evolutionarily stable outcomes of fiscal competition when governments

\footnotetext{
${ }^{1}$ Evolutionary stability is necessary, but not sufficient for this dynamic property. For example, (only) ESS that are strictly globally stable are the unique stable limit points of stochastic processes arising from imitation and experimentation in finite-population games (Alós-Ferrer and Ania, 2005).
} 
have access to two policy variables. We use two workhorse models of fiscal competition originating from Zodrow and Mieszkowski (1986): governments finance, by taxes on mobile capital, the provision of a consumption good (Section 2) or of an input factor into production (Section 3). For both scenarios, the Nash equilibrium allocations differ when government set tax rates or when they set expenditure levels differ (Wildasin, 1991; Bayindir-Upmann, 1998). By contrast, the allocations in the ESS of tax and expenditure games do coincide (Results 2 and 3) - the choice of the policy variable, thus, is irrelevant. In a nutshell, the intuition is as follows: in both models and for any number of jurisdictions, evolutionary stability is tantamount to "competitive behavior", i.e., to the Nash equilibrium that would emerge if there were an infinite number of small, price-taking jurisdictions. $^{2}$ Then, the impact of any jurisdiction's policy choice on the economy-wide allocation and on other jurisdictions' payoffs is negligible. Whether governments set tax rates or expenditure levels is immaterial - and the policy outcomes are therefore identical. This finding should be contrasted with the outcomes in standard Nash play. There, the common root for the non-equivalences of equilibria with different policy variables is that different policy instruments, though linked through budget constraints or other forms of invertible mappings, affect interjurisdictionally mobile items in different ways. This gives rise to different fiscal externalities between jurisdictions which affect the efficiency of policy outcomes differently. With evolutionary play, jurisdictions play competitively, i.e., as if there were no spillovers to other jurisdictions at all. From that perspective, alternative policy instruments are indeed equivalent.

The rest of this paper is structured as follows: Sections 2 and 3 analyzes fiscal interaction when taxes on mobile capital go to finance, respectively, a government-provided consumption good or a production factor. In all scenarios, the allocations at the evolutionarily stable strategies of expenditure and tax games coincide. Section 4 briefly concludes. All proofs are in the Appendix.

\footnotetext{
${ }^{2}$ Competitive behaviour is a common feature of ESS in models of fiscal competition (as well as in various other finite-player settings). It implies that tax competition has most inefficient outcomes, at least in the class of models considered here.
} 


\section{Tax competition with public consumption goods}

\subsection{General description}

We use the seminal framework of tax competition from Zodrow and Mieszkowski (1986, Section 2), Hoyt (1991), and Wildasin $(1988,1991)$. In an economically integrated area there is a finite number $n>1$ of identical jurisdictions. ${ }^{3}$ Each jurisdiction $i \in\{1, \ldots, n\}$ is inhabited by one representative immobile household who owns an unmodeled fixed factor and a given amount of capital $\bar{k}>0$. Capital is costlessly mobile and can be invested at home or in any other jurisdiction.

Each jurisdiction produces a single output $y_{i}$ (which serves as the numéraire), employing the fixed factor and the capital, $k_{i}$, invested in $i$. Technology is represented by a production function $y_{i}=f\left(k_{i}\right)$, with $f^{\prime}(k)>0>f^{\prime \prime}(k)$ for all $k>0$. To avoid uninteresting corner solutions, we assume that $f$ satisfies the Inada conditions $f^{\prime}(0) \rightarrow \infty$ and $f^{\prime}(\infty) \rightarrow 0$. Local output $y_{i}$ can be transformed into consumption, $c_{i}$, or a government-provided good, $z_{i}$, at a marginal rate of transformation of one. Local governments finance the provision of the government good with a proportional tax on the capital invested in their jurisdiction. Denoting the capital tax rate in jurisdiction $i$ by $t_{i}$, tax revenues in $i$ amount to $t_{i} k_{i}$. Governments maintain balanced budgets; expenditures for the public good must equal tax revenues:

$$
z_{i}=t_{i} k_{i}
$$

Private consumption in jurisdiction $i$ emerges as output minus local taxes plus the repatriated return on net capital exports:

$$
c_{i}=f\left(k_{i}\right)-t_{i} k_{i}+\rho\left(\bar{k}-k_{i}\right) .
$$

Welfare in jurisdiction $i=1, \ldots, n$ is represented by a utility function (of a representative individual, say) and depends on the consumption levels of the private and of the publicly-

\footnotetext{
${ }^{3}$ Zodrow and Mieszkowski (1986) originally model a purely competitive setup; in this specification follows Hoyt (1991) and Wildasin (1998). Wildasin (1998) assumes that capital owners reside outside the system of jurisdictions. This gives rise to different values for private consumption than below - without affecting any of the results to come.
} 
provided good:

$$
u^{i}=U\left(c_{i}, z_{i}\right)
$$

Here, $U$ is strictly monotonically increasing in both arguments and strictly quasi-concave. Partial derivatives of $U$ are denoted through subscripts. We assume that both $c$ and $z$ are normal goods. ${ }^{4}$

As the marginal rate of transformation between $c$ and $z$ is one, an efficient allocation in the economy requires that, in every jurisdiction, ${ }^{5}$

$$
k_{i}=\bar{k} \quad \text { and } \quad \frac{U_{z}\left(c_{i}, z_{i}\right)}{U_{c}\left(c_{i}, z_{i}\right)}=1 .
$$

Due to the perfect mobility of capital, the net-of-tax return on capital will be equalized across jurisdictions in a capital market equilibrium. With tax rates $\mathbf{t}=\left(t_{1}, \ldots, t_{n}\right)$, a capital market equilibrium is a distribution of capital $\left(k_{1}(\mathbf{t}), \ldots, k_{n}(\mathbf{t})\right)$ and an after-tax return $\rho(\mathbf{t})$ of capital such that:

$$
\sum_{i=1}^{n} k_{i}(\mathbf{t})=n \cdot \bar{k} \quad \text { and } \quad f^{\prime}\left(k_{i}(\mathbf{t})\right)-t_{i}=\rho(\mathbf{t}) \quad \text { for } i=1, \ldots, n .
$$

The comparative statics of the capital market equilibrium are straighforward: ${ }^{6}$ higher taxes in jurisdiction $i$ lead to an outflow of capital from there $\left(\partial k_{i} / \partial t_{i}<0\right)$, to an inflow of capital into other jurisdictions $\left(\partial k_{j} / \partial t_{i}>0\right)$, and to a drop in the equilibrium of return $\left(\partial \rho / \partial t_{i}<0\right)$.

${ }^{4}$ Formally, $U_{z z} U_{c}-U_{c z} U_{z}<0$ and $U_{c c} U_{z}-U_{c z} U_{c}<0$. This assumption ensures that $\partial\left(U_{z} / U_{c}\right) / \partial z<0$.

${ }^{5} \mathrm{An}$ efficient outcome is obtained by solving, for any non-negative weights $\left(\lambda_{1}, \ldots, \lambda_{n}\right)$,

$$
\max _{c_{i}, z_{i}, k_{i}} \sum_{i} \lambda_{i} u\left(c_{i}, z_{i}\right) \quad \text { s.t. } \quad \sum_{i} k_{i}=n \bar{k} \quad \text { and } \quad \sum_{i}\left(f\left(k_{i}\right)-z_{i}-c_{i}\right) \geq 0 .
$$

Production efficiency $\left(f^{\prime}\left(k_{i}\right)=f^{\prime}\left(k_{j}\right)\right)$ then requires $k_{i}=k_{j}=\bar{k}$. In an equal-treatment allocation, the $c_{i}$ and $z_{i}$ in (1) would be equal across jurisdictions; (1) still allows for interjurisdictional transfers.

${ }^{6}$ They can be obtained from (2) via the Implicit Function Theorem. Specifically, for all $i$ and $j \neq i$,

$$
\begin{aligned}
\frac{\partial k_{i}(\mathbf{t})}{\partial t_{i}} & =\frac{1}{f^{\prime \prime}\left(k_{i}\right)} \cdot\left(1-\frac{1 / f^{\prime \prime}\left(k_{i}\right)}{\sum_{h=1}^{n} 1 / f^{\prime \prime}\left(k_{h}\right)}\right)<0, \\
\frac{\partial k_{j}(\mathbf{t})}{\partial t_{i}} & =-\frac{1}{f^{\prime \prime}\left(k_{i}\right) f^{\prime \prime}\left(k_{j}\right) \sum_{h=1}^{n} 1 / f^{\prime \prime}\left(k_{h}\right)}>0, \\
\frac{\partial \rho(\mathbf{t})}{\partial t_{i}} & =-\frac{1}{f^{\prime \prime}\left(k_{i}\right) \sum_{h=1}^{n} 1 / f^{\prime \prime}\left(k_{h}\right)}<0 .
\end{aligned}
$$




\subsection{Tax vs. expenditure game}

Given $\mathbf{t}$ and attending capital allocation $\left(k_{1}(\mathbf{t}), \ldots, k_{n}(\mathbf{t})\right)$, the tax revenues of jurisdiction $i$ at tax vector $\mathbf{t}$ are $T_{i}(\mathbf{t}):=t_{i} k_{i}(\mathbf{t})$. In vector notation, governments' budget constraints can be written as:

$$
\mathbf{z}=\mathbf{T}(\mathbf{t})
$$

We henceforth assume that the mapping $\mathbf{T}: \mathbf{t} \mapsto \mathbf{z}$ is invertible at any $\mathbf{t}$ : for every $\mathbf{z}$, there exists tax vector $\boldsymbol{\tau}(\mathbf{z})=\left(\tau_{1}(\mathbf{z}), \ldots, \tau_{n}(\mathbf{z})\right)$ such that $\mathbf{z}=\mathbf{T}(\boldsymbol{\tau}(\mathbf{z}))$. The partial derivatives $\mathrm{d} \tau_{i} / \mathrm{d} z_{i}$ and $\mathrm{d} \tau_{j} / \mathrm{d} z_{i}$ measure the changes in tax rates that are necessary in, respectively, jurisdictions $i$ and $j$, to keep all budgets balanced when jurisdiction $i$ changes its expenditure level (see Appendix A.1 for details).

When choosing policies, governments care for the utility of their representative citizens and take into account that capital relocates upon policy changes. With respect to government's strategy variable, we distinguish between tax games and expenditure games.

- Tax game: Each government chooses its tax rate $t_{i}$, taking the tax rates $\mathbf{t}_{-i}$ of the other governments as given and taking into account that

$$
\begin{aligned}
c_{i} & =c_{i}(\mathbf{t})=f\left(k_{i}(\mathbf{t})\right)-t_{i} k_{i}(\mathbf{t})+\rho(\mathbf{t})\left(\bar{k}-k_{i}(\mathbf{t})\right), \\
z_{i} & =t_{i} k_{i}(\mathbf{t}) .
\end{aligned}
$$

In a tax game, jurisdiction $i$ 's payoff at taxes $\mathbf{t}$ and the attending capital market equilibrium can be expressed as

$$
\pi^{t}\left(t_{i} ; \mathbf{t}_{-i}\right)=U\left(f\left(k_{i}(\mathbf{t})\right)-t_{i} k_{i}(\mathbf{t})+\rho(\mathbf{t})\left(\bar{k}-k_{i}(\mathbf{t})\right), t_{i} k_{i}(\mathbf{t})\right)
$$

- Expenditure game: Each government chooses its expenditure level $z_{i}$, taking the expenditure levels $\mathbf{z}_{-i}$ of all other governments as given and taking into account that

$$
\begin{aligned}
c_{i} & =c_{i}(\boldsymbol{\tau}(\mathbf{z}))=f\left(k_{i}(\boldsymbol{\tau}(\mathbf{z}))\right)-\tau_{i}(\mathbf{z}) k_{i}(\boldsymbol{\tau}(\mathbf{z}))+\rho(\boldsymbol{\tau}(\mathbf{z}))\left(\bar{k}-k_{i}(\boldsymbol{\tau}(\mathbf{z}))\right. \\
z_{i} & =\tau_{i}(\mathbf{z}) k_{i}(\boldsymbol{\tau}(\mathbf{z}))
\end{aligned}
$$


In an expenditure game, jurisdiction $i$ 's (absolute) payoff at expenditure levels $\mathbf{z}$ and the attending capital market equilibrium can be expressed as

$$
\pi^{z}\left(z_{i} ; \mathbf{z}_{-i}\right)=U\left(f\left(k_{i}(\boldsymbol{\tau}(\mathbf{z}))\right)-\tau_{i}(\mathbf{z}) k_{i}(\boldsymbol{\tau}(\mathbf{z}))+\rho(\boldsymbol{\tau}(\mathbf{z}))\left(\bar{k}-k_{i}(\boldsymbol{\tau}(\mathbf{z})), z_{i}\right)\right.
$$

With identical jurisdictions, payoff functions (4) and (5) are symmetric: payoffs do not depend on a jurisdiction's index and are invariant to permutations of the other jurisdictions' strategies.

\subsection{Solution concepts}

As all games in this paper are symmetric, we focus on symmetric outcomes. Let us recall the definitions of symmetric Nash equilibrium and (finite-population) evolutionarily stable strategy (ESS) for a generic, symmetric $n$-player game with strategies $\mathbf{x}$, individual strategy sets $X$, and payoff functions $\pi_{i}^{x}(\mathbf{x})$; in our application, " $x$ " is meant to indicate a tax game $(x=t)$ or an expenditure game $(x=z)$.

Definition 1 Suppose, a finite-player $x$-game is played (with $x=t, z$ ).

- A strategy $x^{N} \in X$ is played in a symmetric Nash equilibrium of if

$$
\pi^{x}\left(x^{N} ; x^{N}, \ldots, x^{N}\right) \geq \pi^{x}\left(x ; x^{N}, \ldots, x^{N}\right) \quad \text { for all } x \in X \text {. }
$$

- A strategy $x^{E} \in X$ is said to be an evolutionarily stable strategy (ESS) if

$$
\pi^{x}\left(x^{E} ; x, x^{E}, \ldots, x^{E}\right) \geq \pi^{x}\left(x ; x^{E}, \ldots, x^{E}\right) \quad \text { for all } x \in X
$$

In a Nash equilibrium no jurisdiction would earn a higher absolute payoff from a deviation, given the policy choice of the other jurisdictions. At an evolutionarily stable profile no jurisdiction can gain a strict relative advantage over the other jurisdictions by deviating; the payoff comparison is between a (single) deviator, who chooses policy $x$, and the nondeviators, who all stick to $x^{E}$.

The ESS can be understood as the Nash equilibrium when governments care about their relative performance (Schaffer, 1988). Formally, an ESS is a strategy $x^{E}$ such that

$$
x^{E}=\arg \max _{x \in X}\left[\pi^{x}\left(x ; x^{E}, \ldots, x^{E}\right)-\pi^{x}\left(x^{E} ; x, x^{E}, \ldots, x^{E}\right)\right] .
$$


A finite-population ESS generally is not a Nash equilibrium strategy of the "absolute" game (for a discussion, see Hehenkamp et al., 2010). Deviating from a Nash equilibrium may pay off in relative terms even if it goes along with a reduction in (absolute) payoffs. Sano (2012), Wagener (2013) and Philipowski (2015) have shown that in tax rate competition (i.e., for the tax games discussed here and in Section 3) Nash equilibria and ESS do indeed differ significantly, the latter leading to competitive behavior. Below we show that the same holds for expenditure games, implying that, while Nash equilibria differ between tax and expenditure games, the ESS are the same.

\subsection{Symmetric situations}

Let us introduce some special notation for symmetric situations. When all jurisdictions set the same tax rate (i.e., if $\mathbf{t}=(t, \ldots, t)$ for some $t$ ), then $k_{i}(\mathbf{t})=\bar{k}$ for all $i$. Attending are levels of private consumption, $\bar{c}(t)$, and of public consumption, $\bar{g}(t)$, that are identical across jurisdictions, but that vary with $t$. They are given through

$$
\bar{c}(t)=f(\bar{k})-t \bar{k} \quad \text { and } \quad \bar{z}(t)=t \bar{k} .
$$

We denote by

$$
M R S(t):=\frac{U_{z}(\bar{c}(t), \bar{z}(t))}{U_{c}(\bar{c}(t), \bar{z}(t))}
$$

the marginal rate of substitution between private consumption and public good at a symmetric tax vector with rate $t$. Observe that $M R S(t)$ only depends on $t$ (and parametrically on $\bar{k}$ ), but not on $n$.

A symmetric expenditure vector $\left(z_{i}=z\right.$ for all $\left.i\right)$ can be financed by symmetric tax rates: $t_{i}=z / \bar{k}$ for all $i$. Given the invertibility of $\mathbf{T}$, this solution is unique. Again, if all jurisdictions provide the same level of $z$, they attract the same amount of capital, $\bar{k}$. For symmetric expenditure vectors $\mathbf{z}=(z, \ldots, z)$ denote by $\tau(z)=z / \bar{k}$ the symmetric tax rate that would finance $z$ everywhere.

Starting from a symmetric tax vector, the changes in the capital market equilibrium if one jurisdiction, say $i$, slightly changes its tax rate are given by

$$
\frac{\partial k_{i}}{\partial t_{i}}=\frac{1}{f^{\prime \prime}(\bar{k})} \cdot\left(1-\frac{1}{n}\right)<0 \quad \text { and } \quad \frac{\partial k_{j}}{\partial t_{i}}=-\frac{1}{n f^{\prime \prime}(\bar{k})}>0
$$


for all $i \neq j$. As shown in Appendix A.1, with symmetric expenditures a marginal change in jurisdiction $i$ 's provision level necessitates the following changes in tax rates to keep all budgets balanced:

$$
\frac{\partial \tau_{i}}{\partial z_{i}}=\frac{1+\frac{1}{n} \frac{\tau}{k f^{\prime \prime}(\bar{k})}}{\bar{k}\left(1+\frac{\tau}{k f^{\prime \prime}(\bar{k})}\right)} \quad \text { and } \quad \frac{\partial \tau_{j}}{\partial z_{i}}=\frac{\frac{1}{n} \frac{\tau}{k f^{\prime \prime}(\bar{k})}}{\bar{k}\left(1+\frac{\tau}{k f^{\prime \prime}(\bar{k})}\right)} .
$$

We will henceforth assume that

$$
-\bar{k} f^{\prime \prime}(\bar{k})>\tau
$$

always holds. This ensures that $\frac{\partial \tau_{i}}{\partial z_{i}}>0>\frac{\partial \tau_{j}}{\partial z_{i}}$ : if a jurisdiction wishes to raise its expenditures it has to increase its tax rate - while other jurisdictions can lower their tax rates (which appears plausible, given that they experience an inflow in capital).

\subsection{Nash equilibria}

As shown in Appendix A.2, symmetric Nash equilibria of tax and expenditure games satisfy, respectively,

$$
\begin{aligned}
M R S\left(t^{N}\right) & =\left(1+\frac{t^{N}}{\bar{k} f^{\prime \prime}(\bar{k})}\left(1-\frac{1}{n}\right)\right)^{-1} \\
M R S\left(\tau\left(z^{N}\right)\right) & =\left(1+\frac{\tau\left(z^{N}\right)}{n \bar{k} f^{\prime \prime}(\bar{k})}\right) \cdot\left(1+\frac{\tau\left(z^{N}\right)}{\bar{k} f^{\prime \prime}(\bar{k})}\right)^{-1} .
\end{aligned}
$$

Result 1 The Nash equilibria both of the tax and expenditure game involve under-provision of the publicly provided good. This under-provision is more pronounced in the expenditure game:

$$
\tau\left(z^{N}\right)<t^{N} \quad \text { and } \quad z^{N}<z\left(t^{N}\right)
$$

For additively separable utility functions, (13) has already been shown by Wildasin (1988). Result 1 generalizes this to welfare functions where private and public consumption are normal goods.

\subsection{Evolutionary stability in tax and expenditure games}

Or main result shows that the ESS in tax and expenditure games coincide and are independent of how many jurisdictions there are: 
Result 2 For an ESS of both the tax and the expenditure game, it holds true that

$$
\operatorname{MRS}\left(t^{E}\right)=\left(1+\frac{t^{E}}{\bar{k} f^{\prime \prime}(\bar{k})}\right)^{-1}
$$

independently of the number, $n$, of jurisdictions. Hence,

$$
t^{E}=\tau\left(z^{E}\right) \quad \text { and } \quad z\left(t^{E}\right)=z^{E} .
$$

From Result 2, an ESS in fiscal competition has the following properties:

- Whether the game is played as a tax or an expenditure game, the allocations at an ESS are the same. This should be contrasted with Result 1 which shows that with Nash play the outcomes of tax and expenditure games differ.

- Observe that for $n \rightarrow \infty$, conditions (11) and (12) are identical and coincide with (14). The first observation - that for the "competitive" setting with a very large number of jurisdictions the Nash equilibria of tax- and expenditure games are identical - can already be found in Wildasin (1998, p. 238). The second observation conveys that ESS in fiscal games is identical to competitive behavior. The intuition is as follows: if $n$ gets large, jurisdictions can act as price-takers in Nash play, perceiving themselves (correctly) as not having any impact on the equilibrium rate of return, $\rho$. Likewise, with evolutionary play (= relative payoff maximization), effects on $\rho$ are irrelevant as they are common to all jurisdictions and do not alter relative positions of jurisdictions; this holds regardless of the number of jurisdictions. Hence, "competitive" Nash play and evolutionary play entail the same rationale. ${ }^{7}$

- Compared to Nash play (conditions (11) and (12)), evolutionary play severely exacerbates the under-provision problem. This is can be intuitively understood by recalling that finite-player ESS are Nash equilibria of games played with relative performance concerns (see (6)). Such concerns involve a motive of spite: improving one's own relative standing can also be achieved by harming others - which happens through tax or expenditure cuts (for details see Wagener, 2013).

\footnotetext{
${ }^{7}$ This result is in line with observations in the literature on oligopoly. For example, the ESS in Cournot games coincides with the Walrasian (= price-taking, competitive) outcome (see Vega-Redondo, 1997; Alòs-Ferrer and Ania, 2005).
} 


\section{Tax competition with publicly provided inputs}

So far, tax revenues went to finance the provision of a consumption good. Zodrow and Mieszkowski (1986), Bayindir-Upmann (1998), or Dhillon et al. (2007) discuss scenarios where tax revenues finance a publicly provided input. It is then unclear whether tax competition triggers an under- or an overprovision of the public input. This makes fiscal competition with public inputs an interesting object of study also for evolutionary play.

\subsection{The model}

As before, there are $n>1$ identical jurisdictions, each inhabited by an immobile household who owns the fixed factor and some fixed amount of mobile capital $\bar{k}>0$. The numéraire output $y_{i}$ in each jurisdiction can, at a unit marginal rate of transformation, be used either for consumption, $c_{i}$, or as a publicly provided input into production, $z_{i}$ (say, infrastructure). Technology is then represented by a strictly quasi-concave production function $y_{i}=f\left(k_{i}, z_{i}\right)$ with positive, but decreasing marginal productivities of both capital and the publicly provided input $\left(f_{k}(k, z), f_{z}(k, z)>0\right.$ and $\left.f_{k k}(k, z), f_{z z}(k, z)<0\right)$. The Inada conditions are assumed to hold.

As before, government expenditures are financed through a source tax on capital. Government $i$ 's budget constraint requires $t_{i} k_{i}=z_{i}$. Consumption is given by

$$
c_{i}=y_{i}-t_{i} k_{i}+\rho\left(\bar{k}-k_{i}\right)
$$

and the no-arbitrage condition implicitly defines equilibrium rate of return on capital, $\rho$ :

$$
f_{k}\left(k_{i}, z_{i}\right)-t_{i}=\rho \text { for all } i
$$

The representative household only cares for consumption. Benevolent governments, thus, pursue the maximization of $c_{i}$ as their policy objective: $\pi_{i}=c_{i}$. 
An efficient allocation in this economy requires that, in every jurisdiction, ${ }^{8}$

$$
k_{i}=\bar{k} \quad \text { and } \quad z_{i}=z^{*}, \quad \text { where } z^{*} \text { solves } f_{z}\left(\bar{k}, z^{*}\right)=1 \text {. }
$$

\subsection{Tax and expenditure games}

We again distinguish between tax and expenditure game:

Tax game: Governments set tax rates, and financial resources for $z_{i}$ are determined by balancing the budget. Replacing $z_{i}$ by $t_{i} k_{i}$ in (15) and obeying the requirement that all capital be invested somewhere in the economic area $\left(\sum k_{i}=n \cdot \bar{k}\right)$, the capital market equilibrium can be expressed as a function of tax rates $\mathbf{t}=\left(t_{1}, \ldots, t_{n}\right): k_{i}=k_{i}(\mathbf{t})$ and $\rho=\rho(\mathbf{t})$. Government payoffs in a tax game emerge as

$$
\pi_{i}^{t}=\pi^{t}\left(t_{i} ; \mathbf{t}_{-i}\right)=f\left(k_{i}(\mathbf{t}), t_{i} k_{i}(\mathbf{t})\right)-t_{i} k_{i}(\mathbf{t})+\rho(\mathbf{t}) \cdot\left(\bar{k}-k_{i}(\mathbf{t})\right) .
$$

For symmetric tax vectors $\mathbf{t}=(t, \ldots, t)$, such that $k_{i}=\bar{k}$ everywhere, we define shortcuts

$$
A^{t}(t):=f_{k k}(\bar{k}, t \bar{k})+t \cdot f_{k z}(\bar{k}, t \bar{k}) \quad \text { and } \quad B^{t}(t):=\bar{k} \cdot f_{k z}(\bar{k}, t \bar{k})-1
$$

For symmetric t, comparative statics under the condition that government budgets balance are given by: ${ }^{9}$

$$
\frac{\partial k_{i}}{\partial t_{i}}=-\frac{n-1}{n} \cdot \frac{B^{t}(t)}{A^{t}(t)} \text { and } \quad \frac{\partial k_{j}}{\partial t_{i}}=\frac{1}{n} \cdot \frac{B^{t}(t)}{A^{t}(t)} .
$$

Higher taxes in a jurisdiction will decrease the amount of capital invested there and, consequently, increase the amount of capital elsewhere if and only if $B^{t}(t) / A^{t}(t)<0$.

${ }^{8}$ An efficient outcome solves

$$
\max _{z_{i}, k_{i}} \sum_{i} c_{i}=\sum_{i}\left(f\left(k_{i}, z_{i}\right)-z_{i}\right) \quad \text { s.t. } \quad \sum_{i} k_{i}=n \bar{k} .
$$

Production efficiency $\left(f^{\prime}\left(k_{i}\right)=f^{\prime}\left(k_{j}\right)\right)$ then requires $k_{i}=k_{j}=\bar{k}$.

${ }^{9}$ For arbitrary tax vectors, define shortcuts $A_{i}^{t}:=f_{k k}\left(k_{i}, t_{i} k_{i}\right)+t_{i} \cdot f_{k z}\left(k_{i}, t_{i} k_{i}\right)$ and $B_{i}^{t}:=k_{i}$. $f_{k z}\left(k_{i}, t_{i} k_{i}\right)-1$ for $i=1, \ldots, n$. Then comparative statics are as follows:

$$
\frac{\partial k_{i}(\mathbf{t})}{\partial t_{i}}=-\frac{B_{i}^{t} \sum_{h \neq i} \frac{1}{A_{h}^{t}}}{A_{i}^{t} \sum_{h=1}^{n} \frac{1}{A_{h}^{t}}} \quad \text { and } \quad \frac{\partial k_{i}(\mathbf{t})}{\partial t_{j}}=\frac{B_{j}^{t}}{A_{i}^{t} A_{j}^{t} \sum_{h=1}^{n} \frac{1}{A_{h}^{t}}}
$$

(where $i \neq j$ ). The symmetric case follows easily. 
The reason why the effect is ambiguous is that higher taxes reduce the after-tax return on capital but also allow for higher levels of public inputs, which might enhance the marginal productivity of capital.

Expenditure game: Governments set expenditures $z_{i}$, and the tax rates to finance $z_{i}$ then emerge from the budget constraint as $t_{i}=z_{i} / k_{i}$. Replacing this in (15), the capital market equilibrium can be expressed as a function of expenditures z. Government payoffs in a tax game, $\pi_{i}^{z}=c_{i}$ emerge as

$$
\pi_{i}^{z}=\pi^{z}\left(z_{i} ; \mathbf{z}_{-i}\right)=f\left(k_{i}(\mathbf{z}), z_{i}\right)-z_{i}+\rho(\mathbf{z}) \cdot\left(\bar{k}-k_{i}(\mathbf{z})\right)
$$

We focus on symmetric policies $\left(z_{i}=z\right.$ and $k_{i}=\bar{k}$ for all $\left.i\right)$ and define shortcuts

$$
A^{z}(z):=\bar{k} f_{k k}(\bar{k}, z)+\frac{z}{\bar{k}} \quad \text { and } \quad B^{z}(z):=\bar{k} f_{k z}(\bar{k}, z)-1
$$

For symmetric $\mathbf{z}=(z, \ldots, z)$, comparative statics under the condition that government budgets balance are given by: ${ }^{10}$

$$
\frac{\partial k_{i}}{\partial z_{i}}=-\frac{n-1}{n} \cdot \frac{B^{z}(z)}{A^{z}(z)} \text { and } \quad \frac{\partial k_{j}}{\partial z_{i}}=\frac{1}{n} \cdot \frac{B^{z}(z)}{A^{z}(z)}
$$

Higher expenditures in a jurisdiction will decrease the amount of capital invested there and, consequently, increase the amount of capital elsewhere if and only if $A^{z}(z) / B^{z}(z)<0$.

\subsection{Nash equilibria}

It is well-known that the Nash equilibria of tax and expenditure games implement different allocations. Specifically, symmetric Nash equilibria of tax game $\left(t_{i}=t^{N}\right.$ for all $\left.i\right)$ and expenditure game $\left(z_{i}=z^{N}\right.$ for all $\left.i\right)$ satisfy, respectively,

$$
\begin{aligned}
f_{z}\left(\bar{k}, t^{N} \bar{k}\right)-1 & =\frac{t^{N} f_{z}\left(\bar{k}, t^{N} \bar{k}\right)}{\bar{k}} \cdot \frac{n-1}{n} \cdot \frac{B^{t}\left(t^{N}\right)}{A^{t}\left(t^{N}\right)} \\
& =\frac{B^{t}\left(t^{N}\right) / A^{t}\left(t^{N}\right)}{\frac{n}{n-1} \frac{\bar{k}}{t^{N}}-B^{t}\left(t^{N}\right) / A^{t}\left(t^{N}\right)}, \\
f_{z}\left(\bar{k}, z^{N}\right)-1 & =\frac{z^{N}}{\bar{k}} \cdot \frac{n-1}{n} \cdot \frac{B^{z}\left(z^{N}\right)}{A^{z}\left(z^{N}\right)}
\end{aligned}
$$

\footnotetext{
${ }^{10}$ For arbitrary, non-symmetric tax vectors, an analogous description as in the previous footnote applies.
} 
(also see Bayindir-Upmann, 1998, eqs. (12) and (18)). These conditions generically do not coincide. Hence, in general

$$
z^{N} \neq t^{N} \cdot \bar{k}
$$

Depending on whether $B^{x} / A^{x}$ is positive or negative, conditions (21) and (22) indicate under- or over-provision of the publicly financed input in the tax game $(x=t)$ or the expenditure game $(x=z)$; both outcomes can arise in either game (Bayindir-Upmann, 1998, Props. 4.1 and 4.2).

A knife-edge case where the Nash equilibria of tax and expenditure game coincide arises if $B^{t}\left(t^{N}\right)=0$ or, which is the same, if $B^{z}\left(z^{N}\right)=0$. From (21) and (22), the alloctions in these Nash equilibria are efficient: $f_{z}(\bar{k}, z)=1$ (also see Appendix A.7).

\subsection{Evolutionary stability}

To derive the ESS, we proceed as in Section 2.6. In Appendix A.6 we show that the ESS of the tax game, $t^{E}$, and of the expenditure game, $z^{E}$, satisfy, respectively,

$$
\begin{aligned}
f_{z}\left(\bar{k}, t^{E} \bar{k}\right)-1 & =\frac{B^{t}\left(t^{E}\right) / A^{t}\left(t^{E}\right)}{\frac{\bar{k}}{t^{E}}-B^{t}\left(t^{E}\right) / A^{t}\left(t^{E}\right)}, \\
f_{z}\left(\bar{k}, z^{E}\right)-1 & =\frac{z^{E}}{\bar{k}} \cdot \frac{B^{z}\left(z^{E}\right)}{A^{z}\left(z^{E}\right)} .
\end{aligned}
$$

These conditions convey a number of (by now familiar) messages:

- First, observe that conditions (24) and (25) do not depend on $n$ : in either game, the ESS is the same, regardless of the number of jurisdictions.

- Moreover, the ESS conditions equal the respective conditions (21) and (22) for Nash equilibria if $n \rightarrow \infty$. I.e., evolutionary stability is, both in the tax and the expenditure game, identical with playing "competitive" Nash equilibria. Compared to fiscal competition with Nash play, inefficiencies are, thus, exacerbated. In contrast to the framework in Section 2, inefficiency here may imply over-provison of government goods (i.e., too high tax rates). Evolutionary play, thus, does not only accelerate races-to-the-bottom, it also speeds up races-over-the-top. 
- In the knife-edge case where Nash equilibria (of tax and expenditure game) lead to efficiency, the ESS in either game coincides with the Nash equilibrium - and also implements an efficient allocation. ${ }^{11}$

Most importantly in our context, conditions (24) and (25) are in fact equivalent:

Result 3 In fiscal games where tax revenues go to finance production factors, the allocations at the ESS for tax and expenditure games coincide:

$$
t^{E}=\bar{k} \cdot z^{E}
$$

For the tax-financed provision of production inputs, Result 3 and its contrast with (23) convey the same message as Result 2 for the tax-financed provision of consumption goods.

\section{Concluding remarks}

In simple tax competition games the choice of the strategy variable does not matter in evolutionary play. "Simple" refers to games where vectors of potential policy variables are linked by a one-to-one mapping, in our examples reflected in the collection of government budget constraints.

This observation is driven by the fact that evolutionary play leads to competitive, aggregate-taking behavior in fiscal competition. From such a "small jurisdiction"-perspective, no government perceives its policy to impact on other jurisdictions' payoffs or the equilibrium rate of return in capital markets. This renders all domestic policy instruments equivalent. By consequence, with evolutionary play, all policy issues that arise from the non-equivalence of Nash equilibria in interjurisdictional games played with different variables (see Section 1) cease to matter.

Our results clearly do not imply that the choice of the policy variable never matters in evolutionary play for any type of fiscal interactions. We deliberately confined the analysis to seminal workhorse models of tax competition. This basic framework has undergone

\footnotetext{
${ }^{11}$ If $t$ solves $(21)$ with $B^{t}(t)=0$, the same $t$ also solves (24). This reasoning analogously applies to (22) and (25). Corollary 2 in Hehenkamp et al. (2010) proves that the property that the identity of Nash equilibrium and ESS implies efficiency in fact holds generally in symmetric games.
} 
many interesting modifications and extensions. If and how the choice of strategy variable matters in evolutionary in these variants is an open question for future research.

\section{References}

Alòs-Ferrer, Carlos, and Ana B. Ania (2005): The Evolutionary Stability of Perfectly Competitive Behavior. Economic Theory 26, 497-516.

Alòs-Ferrer, Carlos, and Karl Schlag (2009): Imitation and Learning. In: Paul Anand, Prasanta Pattanaik, and Clemens Puppe, eds., Handbook of Rational and Social Choice, Oxford University Press, pp. 271-296.

Ania, Ana B., and Andreas Wagener (2014): Laboratory Federalism: The Open Method of Coordination (OMC) as an Evolutionary Learning Process. Journal of Public Economic Theory 16, 767-795.

Bayindir-Upmann, Thorsten (1998): Two Games of Interjurisdictional Competition When Local Governments Provide Industrial Public Goods. International Tax and Public Finance 5, 471-487.

Dhillon, Amrita, Myrna Wooders, and Ben Zissimos (2007): Tax Competition Reconsidered. Journal of Public Economic Theory 9, 391-423.

Fudenberg, Drew, and Lorens A. Imhof (2006): Imitation Processes with Small Mutations. Journal of Economic Theory 131, 251-262.

Hauptmeier, Sebastian, Ferdinand Mittermaier, and Johannes Rincke (2012): Fiscal Competition over Taxes and Public Inputs. Regional Science and Urban Economics 42, 407-419.

Hehenkamp, Burkhard, Alex Possajennikov, and Tobias Guse (2010): On the Equivalence of Nash and Evolutionary Equilibrium in Finite Populations. Journal of Economic Behavior \& Organization 73, 254-258. 
Hindriks, Jean (1999): The Consequences of Labour Mobility for Redistribution: Tax vs. Transfer Competition. Journal of Public Economics 74, 215-234.

Hindriks, Jean, Susana Peralta, and Shlomo Weber (2008): Competing in Taxes and Investment under Fiscal Equalization. Journal of Public Economics 92, 2392-2402.

Hoyt, William H. (1991): Property Taxation, Nash Equilibrium, and Market Power. Journal of Urban Economics 30, 123-131.

Koethenbuerger, Marko (2014): Competition for Migrants in a Federation: Tax or Transfer Competition? Journal of Urban Economics 80, 110-118.

Koethenbuerger, Marko (2011): How Do Local Governments Decide on Public Policy in Fiscal Federalism? Tax vs. Expenditure Optimization. Journal of Public Economics 95, 1516-1522.

Philipowski, Robert (2015): Comparison of Nash and Evolutionary Stable Equilibrium in Asymmetric Tax Competition. Regional Science and Urban Economics 51, 7-13.

Sano, Hiroyuki (2012): Evolutionary Equilibria in Capital Tax Competition with Imitative Learning. Evolutionary and Institutional Economics Review 9, S1-S23.

Schaffer, Mark E. (1988): Evolutionarily Stable Strategies for a Finite Population and a Variable Contest Size. Journal of Theoretical Biology 132, 469-478.

Tanaka, Yasuhito (2000): Stochastically Stable States in an Oligopoly with Differentiated Goods: Equivalence of Price and Quantity Strategies. Journal of Mathematical Economics 34, 235-253.

Vega-Redondo, Fernando (1997): The Evolution of Walrasian Behavior. Econometrica $65,375-384$.

Wagener, Andreas (2013): Tax Competition, Relative Performance, and Policy Imitation. International Economic Review 54, 1251-1264.

Wilson, John D. (1986): A Theory of Interregional Tax Competition. Journal of Urban Economics 19, 296-315. 
Zissimos, Ben, and Myrna Wooders (2008): Public Good Differentiation and the Intensity of Tax Competition. Journal of Public Economics 92, 1105-1121.

Zodrow, George R., and Peter Mieszkowski (1986): Pigou, Tiebout, Property Taxation, and the Underprovision of Local Public Goods. Journal of Urban Economics 19, 356-370. 


\section{Appendix}

\section{A.1 Derivation of (10)}

For the invertibility of (3), we assume that the Jacobian determinant of $\mathbf{T}(\mathbf{t})$ is non-zero for all $\mathbf{t}$ that we consider. Suppose that $\boldsymbol{\tau}(\mathbf{z})$ is such that $\tau_{i}(\mathbf{z}) \cdot k_{i}(\boldsymbol{\tau}(\mathbf{z}))=z_{i}$ for all $i$. If governments marginally change their provision level of $\mathbf{z}$ by dz, this requires tax rates to change as follows

$$
\mathrm{d} \boldsymbol{\tau}=\mathbf{J}_{\mathbf{T}}^{-1}(\boldsymbol{\tau}) \mathrm{d} \mathbf{z}
$$

where $\mathbf{J}_{\mathbf{T}}(\mathbf{t})$ is the Jacobian matrix of $\mathbf{T}$, evaluated at tax vector $\mathbf{t}$ :

$$
\mathbf{J}_{\mathbf{T}}=\left(\begin{array}{ccc}
\frac{\partial T_{1}}{\partial t_{1}} & \cdots & \frac{\partial T_{1}}{\partial t_{n}} \\
\vdots & \ddots & \vdots \\
\frac{\partial T_{n}}{\partial t_{1}} & \cdots & \frac{\partial T_{n}}{\partial t_{n}}
\end{array}\right)
$$

where $\frac{\partial T_{i}}{\partial t_{i}}=k_{i}+t_{i} \frac{\partial k_{i}}{\partial t_{i}}$ and $\frac{\partial T_{j}}{\partial t_{i}}=t_{j} \frac{\partial k_{j}}{\partial t_{i}}($ where $i \neq j)$. Evaluated at a symmetric $\mathbf{t}, \mathbf{J}_{\mathbf{T}}$ takes the form

$$
\mathbf{J}_{\mathbf{T}}=\left(\begin{array}{cccc}
a+b & b & \ldots & b \\
b & a+b & \ldots & b \\
\vdots & \vdots & \ddots & \vdots \\
b & b & \ldots & a+b
\end{array}\right)
$$

with $a:=\bar{k}+t\left(\frac{\partial k_{i}(t)}{\partial t_{i}}-\frac{\partial k_{i}(t)}{\partial t_{j}}\right)$ and $b:=t \frac{\partial k_{i}(t)}{\partial t_{j}}$. Verify that (direct calculation can be done by using Sherman-Morrison formula):

$$
\mathbf{J}_{\mathbf{T}}^{-1}=\frac{1}{a(a+n b)}\left(\begin{array}{cccc}
a+(n-1) b & -b & \ldots & -b \\
-b & a+(n-1) b & \ldots & -b \\
\vdots & \vdots & \ddots & \vdots \\
-b & -b & \ldots & a+(n-1) b
\end{array}\right)
$$

Using (9) we obtain:

$$
\begin{aligned}
\frac{\partial \tau_{i}}{\partial z_{i}} & =\mathbf{J}_{\mathbf{T}}^{-1}(i, i)=\frac{a+(n-1) b}{a(a+n b)}=\frac{\bar{k}+\frac{t}{f^{\prime \prime}(\bar{k}) n}}{\bar{k}\left(\bar{k}+\frac{t}{f^{\prime \prime}(\bar{k})}\right)} \\
\frac{\partial \tau_{j}}{\partial z_{i}} & =\mathbf{J}_{\mathbf{T}}^{-1}(j, i)=-\frac{b}{a(a+n b)}=\frac{\frac{t}{f^{\prime \prime}(\bar{k}) n}}{\bar{k}\left(\bar{k}+\frac{t}{f^{\prime \prime}(\bar{k})}\right)}
\end{aligned}
$$

resulting in (10). 


\section{A.2 Derivation of (11) and (12)}

Tax game: Jurisdiction $i$ 's best response in a $t$-game is implicitly given by

$$
\frac{\partial \pi^{t}\left(t_{i} ; \mathbf{t}_{-i}\right)}{\partial t_{i}}=-U_{c}\left(k_{i}-\frac{\partial \rho}{\partial t_{i}} \cdot\left(\bar{k}-k_{i}\right)\right)+U_{z}\left(t_{i} \cdot \frac{\partial k_{i}}{\partial t_{i}}+k_{i}\right)=0,
$$

where all functions are evaluated at $\mathbf{t}$. With symmetry $\left(t_{i}=t^{N}\right.$ and, consequently, $k_{i}=\bar{k}$ for all $i$ ), rearranging terms leads to (11).

Jurisdiction $i$ 's best response in a $z$-game is implicitly given by

$$
\frac{\partial \pi^{z}\left(z_{i} ; \mathbf{z}_{-i}\right)}{\partial z_{i}}=-U_{c}\left(k_{i}-\frac{\partial \rho}{\partial t_{i}} \cdot\left(\bar{k}-k_{i}\right)\right) \cdot \frac{\partial \tau_{i}}{\partial z_{i}}+U_{z}=0,
$$

where all functions are evaluated at $\boldsymbol{\tau}(\mathbf{z})$. With symmetry, rearranging terms leads to (12).

\section{A.3 Proof of Result 1}

For $t$, define

$$
a(t):=\frac{1}{1+\frac{t}{k f^{\prime \prime}(\bar{k})}\left(1-\frac{1}{n}\right)} \quad \text { and } \quad b(t):=\frac{1+\frac{1}{n} \frac{t}{k f^{\prime \prime}(\bar{k})}}{1+\frac{t}{k f^{\prime \prime}(\bar{k})}} .
$$

Observe that $a(t)$ increases in $t$ :

$$
a^{\prime}(t)=-a(t)^{2} \cdot \frac{1}{\bar{k} f^{\prime \prime}(\bar{k})}\left(1-\frac{1}{n}\right)>0
$$

Moreover, observe that

$$
\begin{aligned}
a(t)>b(t) & \Longleftrightarrow\left(1+\frac{1}{n} \frac{t}{\bar{k} f^{\prime \prime}(\bar{k})}\right)>\left(1+\frac{t}{\bar{k} f^{\prime \prime}(\bar{k})}\right)\left(1+\frac{t}{\bar{k} f^{\prime \prime}(\bar{k})}\left(1-\frac{1}{n}\right)\right) \\
& \Longleftrightarrow \frac{1}{n} \cdot\left(\frac{t}{\bar{k} f^{\prime \prime}(\bar{k})}\right)^{2} \cdot\left(1-\frac{1}{n}\right)>0
\end{aligned}
$$

— which always holds.

Nash equilibria of tax and expenditure game satisfy, respectively, $M R S\left(t^{N}\right)=a\left(t^{N}\right)$ and $\operatorname{MRS}\left(\tau^{N}\right)=b\left(\tau^{N}\right)$. Observe that

$$
\frac{\mathrm{d} M R S(t)}{\mathrm{d} t}=\frac{\bar{k}}{U_{c}^{2}}\left(U_{c} U_{z z}-U_{c} U_{c z}+U_{z} U_{c c}-U_{z} U_{c z}\right)<0
$$

where the derivatives of $U$ are evaluated at $\bar{c}(t)$ and $z=t \bar{k}$. To obtain the above expression we used (7). The sign follows from the normality of both goods (cf. footnote 4). 
We prove the proposition proper by contraposition. Suppose that $t^{N} \leq \tau^{N}$. Then:

$$
b\left(\tau^{N}\right)=M R S\left(\tau^{N}\right) \leq M R S\left(t^{N}\right)=a\left(t^{N}\right)<a\left(\tau^{N}\right)
$$

- which violates the fact that $a(t)>b(t)$ for all $t$. Hence, a contradiction. Consequently, $t^{N}>\tau^{N}$ must hold.

To prove inefficiency, recall that an efficient provision level $z^{*}$ satisfies $M R S=1$. In a symmetric Nash equilibrium we have $M R S\left(t^{N}\right)>1$. Normality of $c$ and $z$ then implies $z\left(t^{N}\right)<z^{*}$.

\section{A.4 Proof of Result 2}

For the tax game, Result 2 in Wagener (2013) shows that an ESS satisfies (14). We therefore confine ourselves to the ESS in the expenditure game. Recalling (6), the payoff difference between a jurisdiction that deviates from a common strategy and a jurisdiction that sticks with it in an expenditure game amounts to

$$
\psi\left(z, z^{\prime}\right):=\pi^{z}\left(\mathbf{z}^{1}\left[z, z^{\prime}\right]\right)-\pi^{z}\left(\mathbf{z}^{2}\left[z, z^{\prime}\right]\right)
$$

where, given $z, z^{\prime} \in Z$, we define vectors

$$
\mathbf{z}^{1}\left[z, z^{\prime}\right]=\left(z ; z^{\prime}, \ldots, z^{\prime}\right) \text { and } \mathbf{z}^{2}\left[z, z^{\prime}\right]=\left(z^{\prime} ; z, z^{\prime}, \ldots, z^{\prime}\right)
$$

Following Tanaka (2000), a strategy $z^{E}$ is an ESS if and only if it solves the problem

$$
\max _{z \in Z} \psi\left(z, z^{\prime}\right)
$$

for $z^{\prime}=z^{E}$, i.e., iff $z^{E}=\arg \max _{z \in Z} \psi\left(z, z^{E}\right)$. For the expenditure game, we get

$$
\begin{aligned}
\psi\left(z, z^{\prime}\right)= & U\left(f \left(k_{1}\left(\boldsymbol{\tau}\left(\mathbf{z}^{1}\right)\right)-\tau_{1}\left(\mathbf{z}^{1}\right) k_{1}\left(\boldsymbol{\tau}\left(\mathbf{z}^{1}\right)\right)+\rho\left(\boldsymbol{\tau}\left(\mathbf{z}^{1}\right)\right)\left(\bar{k}-k_{1}\left(\boldsymbol{\tau}\left(\mathbf{z}^{1}\right)\right), z\right)\right.\right. \\
& -U\left(f \left(k_{2}\left(\boldsymbol{\tau}\left(\mathbf{z}^{2}\right)\right)-\tau_{2}\left(\mathbf{z}^{2}\right) k_{2}\left(\boldsymbol{\tau}\left(\mathbf{z}^{2}\right)\right)+\rho\left(\boldsymbol{\tau}\left(\mathbf{z}^{1}\right)\right)\left(\bar{k}-k_{2}\left(\boldsymbol{\tau}\left(\mathbf{z}^{2}\right)\right), z^{\prime}\right) .\right.\right.
\end{aligned}
$$


Observe that $\rho\left(\boldsymbol{\tau}\left(\mathbf{z}^{1}\right)\right)=\rho\left(\boldsymbol{\tau}\left(\mathbf{z}^{2}\right)\right)$. To find the maximum of (27), we partially differentiate $\psi$ with respect to $z$. Using the Envelope Theorem, we obtain: ${ }^{12}$

$$
\begin{aligned}
\frac{\partial \psi\left(z, z^{\prime}\right)}{\partial z}= & U_{z}^{1}-U_{c}^{1}\left(k_{1}-\frac{\partial \rho\left(\boldsymbol{\tau}\left(\mathbf{z}^{1}\right)\right)}{\partial t_{1}} \cdot\left(\bar{k}-k_{1}\right)\right) \cdot \frac{\mathrm{d} \tau_{1}\left(\mathbf{z}^{1}\right)}{\mathrm{d} z_{1}} \\
& +U_{c}^{2}(\underbrace{\left(f^{\prime}\left(k_{2}\right)-t_{2}-\rho\right)}_{=0} \cdot \frac{\partial k_{2}}{\partial t_{2}}-k_{2}+\frac{\partial \rho\left(\boldsymbol{\tau}\left(\mathbf{z}^{2}\right)\right)}{\partial t_{2}} \cdot\left(\bar{k}-k_{2}\right)) \cdot \frac{\mathrm{d} \tau_{2}\left(\mathbf{z}^{2}\right)}{\mathrm{d} z_{1}} .
\end{aligned}
$$

At a symmetric profile (with $z=z^{\prime}$ ), we have $\mathbf{z}^{1}=\mathbf{z}^{2}$ and $k_{1}=k_{2}=\bar{k}$. Moreover, $c^{1}=c^{2}=f(\bar{k})-z^{\prime}$ and the marginal utilities $U_{c}^{2}$ and $U_{c}^{1}$ coincide as they are both evaluated at $\left(f(\bar{k})-z^{\prime}, z^{\prime}\right)$. Hence,

$$
\frac{\partial \psi\left(z^{\prime}, z^{\prime}\right)}{\partial z}=U_{z}-U_{c} \cdot \bar{k} \cdot\left(\frac{\mathrm{d} \tau_{1}}{\mathrm{~d} z_{1}}-\frac{\mathrm{d} \tau_{2}}{\mathrm{~d} z_{1}}\right)=U_{z}-U_{c} \cdot \frac{\bar{k}}{\bar{k}\left(1+\frac{\tau}{k f^{\prime \prime}(\bar{k})}\right)}
$$

where we used (10). Equating this to zero, gives (14) - as in the ESS of a tax game. Moreover, observe that $n$ does not show up on either side of (14).

\section{A.5 Derivation of (21) and (22)}

First consider the tax game. Best responses are characterized by:

$$
\begin{aligned}
0=\frac{\partial \pi_{i}^{t}}{\partial t_{i}} & =\left(f_{k}-t_{i}-\rho\right) \frac{\partial k_{i}}{\partial t_{i}}-k_{i}+\frac{\partial \rho}{\partial t_{i}}\left(\bar{k}-k_{i}\right)+f_{z}\left(k_{i}+t_{i} \frac{\partial k_{i}}{\partial t_{i}}\right) \\
& =-k_{i}+\frac{\partial \rho}{\partial t_{i}}\left(\bar{k}-k_{i}\right)+f_{z}\left(k_{i}+t_{i} \frac{\partial k_{i}}{\partial t_{i}}\right) .
\end{aligned}
$$

In a symmetric Nash equilibrium $\left(t_{i}=t^{N}\right.$ for all $\left.i\right)$, this condition holds at $k_{i}=\bar{k}$. Using (18) gives $(21)$.

Next consider the expenditure game. Best responses are implicitly defined through:

$$
\begin{aligned}
0=\frac{\partial \pi_{i}^{z}}{\partial z_{i}} & =f_{z}+f_{k} \frac{\partial k_{i}}{\partial z_{i}}-1+\frac{\partial \rho}{\partial z_{i}}\left(\bar{k}-k_{i}\right)-\rho \frac{\partial k_{i}}{\partial z_{i}} \\
& =f_{z}-1+\frac{z_{i}}{k_{i}} \frac{\partial k_{i}}{\partial t_{i}}+\frac{\partial \rho}{\partial z_{i}}\left(\bar{k}-k_{i}\right) .
\end{aligned}
$$

In a symmetric Nash equilibrium $\left(z_{i}=z^{N}\right.$ for all $\left.i\right)$, this condition holds at $k_{i}=\bar{k}$. Using (20) gives (22).

\footnotetext{
${ }^{12}$ We write $\frac{\partial \rho\left(\boldsymbol{\tau}\left(\mathbf{z}^{1}\right)\right)}{\partial t_{1}}$ and $\frac{\partial \rho\left(\boldsymbol{\tau}\left(\mathbf{z}^{2}\right)\right)}{\partial t_{2}}$ as the derivatives of $\rho$ with respect to, respectively, the first component of $\boldsymbol{\tau}\left(\mathbf{z}^{1}\right)$ and the second component of $\boldsymbol{\tau}\left(\mathbf{z}^{2}\right)$. The numerical values of these derivatives are, of course, the same since $\rho\left(\boldsymbol{\tau}\left(\mathbf{z}^{2}\right)=\rho\left(\boldsymbol{\tau}\left(\mathbf{z}^{1}\right)\right.\right.$.
} 


\section{A.6 Derivation of (24) and (25)}

The proof of (24) can be found in Wagener (2013). Therefore let us briefly sketch the proof of (25). We proceed as in Section A.4 and use the same notational conventions. Define payoff differentials between a mutant and a non-mutant jurisdiction as

$$
\psi^{z}\left(z, z^{\prime}\right)=f\left(k_{1}\left(\mathbf{z}^{1}\right), z\right)-z-f\left(k_{2}\left(\mathbf{z}^{2}\right), z^{\prime}\right)+z^{\prime}+\rho\left(\mathbf{z}^{1}\right) \cdot\left(k_{2}\left(\mathbf{z}^{2}\right)-k_{1}\left(\mathbf{z}^{1}\right)\right)
$$

(recall that $\rho\left(\mathbf{z}^{1}\right)=\rho\left(\mathbf{z}^{2}\right)$ ). Partial differentiation with respect to $z$ yields:

$$
\begin{aligned}
\frac{\partial \psi^{z}\left(z, z^{\prime}\right)}{\partial z}= & -1+f_{z}\left(k_{1}\left(\mathbf{z}^{1}\right), z\right)+\frac{\partial \rho\left(\mathbf{z}^{1}\right)}{\partial z} \cdot\left(k_{2}-k_{1}\right) \\
& +\left(f_{k}\left(k_{1}\left(\mathbf{z}^{1}\right), z\right)-\rho\left(\mathbf{z}^{1}\right)\right) \cdot \frac{\partial k_{1}}{\partial z}++\left(f_{k}\left(k_{2}\left(\mathbf{z}^{2}\right), z^{\prime}\right)-\rho\left(\mathbf{z}^{1}\right)\right) \cdot \frac{\partial k_{2}}{\partial z} .
\end{aligned}
$$

At a symmetric profile $\left(z=z^{\prime}\right)$, we have $\mathbf{z}^{1}=\mathbf{z}^{2}, k_{1}=k_{2}=\bar{k}$, and $t_{1}=t_{2}=z / \bar{k}$. Since an ESS $z^{E}$ maximizes $\psi^{z}\left(z, z^{E}\right)$, it satisfies

$$
-1+f_{z}\left(\bar{k}, z^{E}\right)+\frac{z^{E}}{\bar{k}} \cdot\left(\frac{\partial k_{1}}{\partial z}-\frac{\partial k_{2}}{\partial z}\right)=0 .
$$

With (20), this yields (25).

\section{A.7 Proof of Result 3}

The strategy of the proof is to derive conditions such that the allocations in the symmetric Nash equilibria of tax and expenditure game coincide (recall that the ESS is a Nash equilibrium for $n \rightarrow \infty)$. Suppose that $z^{N}=t^{N} \bar{k}$ in the solutions of (21) and (22). Then, the expressions on the LHS of (21) and (22) coincide - and the expressions on the RHS must be equal, too. Moreover, $B^{z}(t \bar{k})=B^{t}(t)$ for all $t$ with $t \bar{k}=z$. Hence,

$$
\begin{aligned}
t^{N} \bar{k}=z^{N} & \Longleftrightarrow \frac{z^{N}}{\bar{k}} \cdot \frac{n-1}{n} \cdot \frac{1}{A^{z}\left(t^{N} \bar{k}\right)}=\frac{1 / A^{t}\left(t^{N}\right)}{\frac{n}{n-1} \frac{\bar{k}}{t^{N}}-B^{t}\left(t^{N}\right) / A^{t}\left(t^{N}\right)} \\
& \Longleftrightarrow \frac{n}{n-1} \frac{\bar{k}}{t^{N}} A^{t}\left(t^{N}\right)-B^{t}\left(t^{N}\right)=\frac{n}{n-1} \frac{\bar{k}}{t^{N} \bar{k}} A^{z}\left(t^{N} \bar{k}\right) \\
& \Longleftrightarrow \frac{n}{n-1} \frac{\bar{k}}{t^{N}}\left(f_{k k}+t^{N} f_{k z}\right)-\bar{k} f_{k z}+1=\frac{n}{n-1} \frac{1}{t^{N}}\left(k f_{k k}+\frac{z^{N}}{\bar{k}}\right) \\
& \Longleftrightarrow \frac{1}{n-1} \cdot\left(\bar{k} f_{k z}\left(\bar{k}, z^{N}\right)-1\right)=0 .
\end{aligned}
$$


Here, all derivatives of $f$ are evaluated at $\left(\bar{k}, z^{N}\right)$. Condition (28) generally does not hold (confirming the generic non-equivalence of Nash equilibria in tax and expenditure games). However, there are precisely two cases where it holds:

(i) $n \rightarrow \infty$ : This is the competitive scenario which, from Result 2 , coincides with the ESS. Hence, $t^{E} \bar{k}=z^{E}$, as claimed in Result 3 .

(ii) $\bar{k} f_{k z}\left(\bar{k}, z^{N}\right)=1$ or, equivalently, $B^{z}\left(z^{N}\right)=B^{t}\left(t^{N}\right)=0$ : In this scenario, the Nash equilibria both of the tax and the expenditure game are efficient. This validates the remarks on the "knife-edge case" in Sections 3.3 and 3.4. Here Nash equilibria, ESS and efficient solutions are identical. 